\title{
Distribusi dan Kemelimpahan Meiofauna di Hulu Sungai Code Yogyakarta
}

\author{
Riche Hariyati \\ Laboratorium Ekologi dan Biosistematik, Jurusan Biologi FMIPA Undip
}

\begin{abstract}
This research is aimed to study distribution and abundance of meiofauna and the quality of physicochemical characteristics of uppersite of code river and up stream river code Yogyakarta province. Samples were taken using modified Pysto style corer and were located based on habitat types specific river, which are pool, riffle, rapid, left side and right side of water column. Sample taken four times for each zone. The parameter of for water quality measured were dissolved oxygen. Water current, alkalinity and $\mathrm{pH}$

Result from the analysis showed that the abundance of meiofauna at code river the highest at left side zone. Which was 537.806 individu/m3 with relative abundance was $28,09 \%$ result from physico chemical parameter of

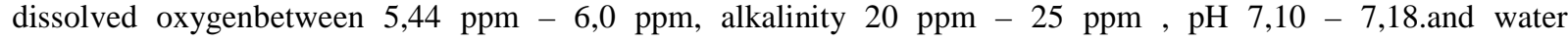
currenntmeasured between $0,03 \mathrm{~m} / \mathrm{sec}-0,49 \mathrm{~m} / \mathrm{sec}$. The abundance of meiofauna at code river was dominated by group of Nematodes horizontal distribution of the fauna was the widest for Nematodes ostracoda, Rhizopoda and insecta. Physico chemicalquality of code river water was relative good for meiofauna habitat and other water organisms
\end{abstract}

Key Words : Distribution, Abundance, Meiofauna

\section{PENDAHULUAN}

Meiofauna merupakan organisme yang hidup di substrat dasar perairan, membuat liang, merayap bebas di atas batu, bahan organik atau substrat lainnya. Umumnya organisme ini mempunyai ukuran lebih kecil dari $0,1 \mathrm{~mm}$. Organisme yang termasuk kedalam kelompok ini adalah Coelenterata, Cladocera, Copepoda, Rotifera, Nematoda, Crustaceae dan Avertebrata lainnya..

Meiofauna yang hidup si sungai mewakili hampir tiap kelompok taksonomi hewan yang ada di air tawar, dan beberapa kelompok hanya dapat hidup di sungai dan dapat mencapai perkembangan maksimum denmgan diversitas yang tinggi. Organisme tersebut antara lain adalah ordo Plecoptera, Ephemeroptera, Tricoptera, Megaloptera dan Oiptera (Hynes, 1970). Pada umumnya meiofauna dapat dijadikan sebagai bioindikator adanya perubahan kualitas air sungai Hal ini dikarenakan meiofauna mempunyai sifat menetap pada substrat tertentu, mempunyai masa hidup yang panjang, keberadaannya konstan dan mempunyai toleransi yang tinggi terutama terhadap kandungan $\mathrm{O}_{2}$ yang rendah.
Penurunan cacah spesies menunjukkan adanya penurunan kualitas lingkungan atau perubahan cacah spesies dapat memberikan gambaran bagi suatu karakteristik komunitas sebagai tanggapan terhadap bahan pencemaran. Kovacs (1992), menyebutkan bahwa bioindikator pada tingkat ekosistem atau komunitas dapat berupa variabel komposisi spesies, kemelimpahan, biomassa dan distribusi dari suatu organisme. Kemelimpahan dan distribusi organisme di suatu perairan dipengaruhi oleh faktor-faktor fisik kimia air antara lain temperatur, kecepatan arus, $\mathrm{pH}$, kedalaman, kandungan oksigen terlarut dan juga dipengaruhi oleh keberadaan organisme itu sendiri karena adanya kompetisi.

Sungai Code di Daerah Istimewa Yogyakarta merupakan tipe sungai yang hampir sama dengan sungai-sungai lain di Indonesia dilihat dari kondisi fisik dan kondisi geologinya. Tipe habitat sungai berdasarkan substrat umumnya terbagi dalam golongan Pool (habitat tenang, substrat lumpur), Riffle (substrat pasir) dan Rapid (substrat batuan). Sungai ini banyak dimanfaatkan oleh masyarakat sekitar untuk memenuhi kebutuhan sehari-hari baik untuk mandi, cuci 
ataupun kakus (MCK). Disamping itu banyak macam industri yang memanfaatkan sungai ini sebagai sumber air bagi proses industri ataupun menggunakannya sebagai tempat pembuangan limbah yang dihasilkan.

Melihat kondisi yang demikian timbul suatu permasalahan bagaimanakah dampak dari perubahan kualitas perairan Sungai Code akibat pembuangan aktivitas rumah tangga dan industri, terhadap distribusi dan kemelimpahan meiofauna di sungai Code. Untuk itu dilakukan suatu kajian untuk mempelajari distribusi horisontal dan kemelimpahan meiofauna serta kualitas fisik kimia perairan sungai tersebut, karena diduga dengan banyaknya aktivitas manusia atau industri pengguna sungai ini akan berpengaruh terhadap kondisi fisik kimia air sungai serta kehidupan organisme perairan terutama organisme meiofaunanya.

\section{BAHAN DAN METODE}

Alat dan bahan yang digunakan adalah modifikasi Pyston-style corer, saringan bertingkat, kantong plastik, termometer $\mathrm{Hg}$,Lup, SRCC, Limnological kit, akuades dan Formalin $4 \%$.

Penentuan titik sampling berdasarkan pada tipe habitat sungai yaitu Zona Pool (substrat lumpur), Riffle, Rapid, Tepi kiri dan Tepi kanan dari arah hulu sungai. Pengambilan sampel pada masing-masing zona dengan ulangan empat kali. Sampel meiofauna diambil dengan menggunakan Pyston-style corer dengan diameter dua inci yang dimasukkan kedalam sedimen atau substrat secara spasial sampai mencapai kedalaman $10 \mathrm{~cm}$. Cuplikan sedimen ini disaring dengan saringan berrtingkat dan difiksasi dengan formalin $4 \%$, selanjutnya diidentifikasi di bawah mikroskop dan dihitung jumlah individu setiap jenis. Parameter fisik kimia perairan diukur secara insitu dengan menggunakan kit LA MOTTE.

Kemelimpahan jenis dan indeks pemeratan penyebaran individu dihitung berdasarkan rumus dari Odum (1971) dan indeks keanekaragaman berdasarkan Shanon-Wiener (Krebs, 1989) .

\section{HASIL DAN PEMBAHASAN}

A. Kemelimpahan dan dominasi meiofauna di Sungai Code

Dari hasil pengamatan dan analisis data diperoleh bahwa kemelimpahan hewan meiofauna tertinggi adalah pada zona tepi kiri (Tki) yaitu sebesar 537.806 individu/m3 dengan nilai indeks kemelimpahan relatif sebesar 28,09\% sedangkan kemelimpahan meiofauna terendah terdapat pada zona rapid yaitu sebesar 296.040 individu /m3 dengan nilai indeks kemelimpahan relatif sebesar $15,46 \%$. Melimpahnya hewan meiofauna pada zona tepi kiri ini dikarenakan adanya satu genus yang dominan yaitu Aphelenchoides yang termasuk dalam kelompok Nematoda sejumlah 177.624 individu/m3. Pada zona rapid mempunyai kemelimpahan relatif rendah karena zona ini berarus kuat sehingga hanya hewan-hewan tertentu yang dapat hidup dan beradaptasi di habitat ini.

Dilihat dari indeks kemelimpahan zona yang paling melimpah hewan meiofauna adalah berturut-turut sebagai berikut zona Tepi Kiri $(28,1 \%)$, Zona tepi kanan $(20,1 \%)$, riffle $(19,34 \%)$, zona pool $(17,00 \%)$ dan zona rapid $(15,5 \%)$. Sedangkan nilai indeks dominasi masing-masing kelompok meiofauna, tertinggi adalah Nematoda $(46,4 \%)$, kemudian berturut-turut Ostracoda $(14,7 \%)$, Rotifera $(13,9 \%)$ sedangkan terendah adalah kelompok Ciliphora sebesar 0,52\%.

Nematoda paling dominan diantara kelompok-kelompok lain karena memiliki 3 (tiga) spesies yang melimpah yaitu Aphelenchoides, Pangrolaimus dan Proseriata dimana ketiga spesies ini distribusinya paling luas dan merata karena terdapat pada semua zona titik sampling. Disamping itu melimpah dan meratanya kelompok nematoda ini dikarenakan mempunyai habitat yang cocok untuk kehidupannya yaitu pada habitat pasir berlumpur. Disamping itu kecepatan arus juga sesuai dengan keberadaanyya pada perairan tersebut yaitu termasuk dalam kategori arus yang lambat karena memiliki kecepatan arus dibawah $0,5 \mathrm{~m} /$ detik (tabel 9). Demikian juga kondisi $\mathrm{pH}$ pada perairan sungai code masih sesuai untuk kehidupan meiobenthos. Seperti dikatakan oleh Harnes (1978) bahwa pH yang baik untuk kehidupan hewan meiofauna berkisar antara 6,7 sampai dengan 7,4. Rendahnya kelompok 
Ciliophora pada perairan ini menunjukkan bahwa perairan sungai code ini kurang sesuai untuk tempat hidupnya karena umumnya kelompok ciliophora lebih menyukai habitat yang tidak berarus atau arusnya relatif tenang.

Dari hasil analisis sebagaimana ditunjukkan tabel 2 keanekaragaman perairan sungai code cukup tinggi berkisar antara 2,597 hingga 3,384. Hal ini menunjukkan perairan sungai code bagian hulu masih baik dalam arti belum tercemar oleh limbah atau bahan organik yang lain. Secara keseluruhan di sungai code bagian hulu ditemukan 70 genus meiofauna

Tabel 1. Jumlah total individu (individu/m3), indeks keanekaragaman, indeks perataan dan indeks kemelimpahan relatif meiofauna di sungai code Yogyakarta

\begin{tabular}{llllll}
\hline & Pool & Riffle & rapid & T kiri & $\begin{array}{l}\text { T } \\
\text { kanan }\end{array}$ \\
\hline Jml tot ind & 325644 & 370050 & 296040 & 537806 & 384852 \\
Indeks kmlmphn rel & 17,0 & 19,33 & 15,46 & 28,09 & 20,10 \\
Indeks knekargmn (H') & 3841 & 2,892 & 2,594 & 3,384 & 2,971 \\
Indeks perataan & 0,518 & 0,588 & 0,381 & 0,366 & 0,521 \\
\hline
\end{tabular}

Tabel 2 Kualitas fisik kimia perairan sungai Code Yogyakarta

\begin{tabular}{llllll}
\hline & Pool & Riffle & Rapid & Tepi kiri & T kanan \\
\hline DO (ppm) & 5,44 & 6,0 & 5,44 & 4,81 & 4,7 \\
Alkalinitas (ppm) & 20 & 25 & 20 & 20 & 21 \\
PH & 7,13 & 7,12 & 7,18 & 7,10 & 7,12 \\
Sedimen & Berlumpur & pasir & pasir & berlumpur & berlumpur \\
& & kasar & lumpur & & \\
Arus (m/detik) & 0,03 & 0,49 & 0,21 & 0,19 & 0,32 \\
Suhu $\left({ }^{\circ} \mathrm{C}\right)$ & 29 & 29 & 29,5 & 29,3 & 29,5 \\
\hline
\end{tabular}

Tabel 3. Indeks Dominasi Masing-masing Kelompok Meiofauna di Sungai Code

\begin{tabular}{lllllll}
\hline \multirow{2}{*}{ Genera } & \multicolumn{5}{c}{ Sungai Code $(\%)$} \\
\cline { 2 - 6 } & Pool & Riffle & Rapid & T.Ki & T.Ka & Jumlah \\
\hline Cladocera & 6.06 & 4.00 & 0.00 & 0.92 & 5.13 & 3.09 \\
Copepoda & 1.52 & 2.67 & 1.67 & 1.83 & 2.56 & 2.06 \\
Ciliphora & 0.00 & 1.33 & 1.67 & 0.00 & 0.00 & 0.52 \\
Crustaceae & 0.00 & 1.33 & 0.00 & 0.00 & 2.56 & 0.77 \\
Insekta & 7.58 & 9.33 & 6.67 & 1.83 & 6.41 & 5.93 \\
Molusca & 4.55 & 0.00 & 3.33 & 2.75 & 2.56 & 2.58 \\
Rotifera & 13.64 & 24.00 & 1.67 & 10.09 & 19.23 & 13.92 \\
Tardigrada & 3.03 & 2.67 & 0.00 & 0.00 & 2.56 & 1.55 \\
Rhizopoda & 9.09 & 6.67 & 3.33 & 7.34 & 6.41 & 6.70 \\
Nematoda & 36.36 & 30.67 & 66.67 & 58.72 & 37.18 & 46.39 \\
Oligochaeta & 0.00 & 1.33 & 6.67 & 0.00 & 2.56 & 1.80 \\
Ostracoda & 18.18 & 16.00 & 8.33 & 16.51 & 12.82 & 14.69 \\
Jumlah & 100.00 & 100.00 & 100.00 & 100.00 & 100.00 & 100.00 \\
(total) & & & & & & \\
\hline
\end{tabular}

Tabel 4. Jumlah Nematoda di Sungai Code, Yogyakarta

\begin{tabular}{lllllll}
\hline Nematoda & \multicolumn{7}{c}{ Sungai Code } \\
\cline { 2 - 7 } & Pool & Riffle & Rapid & T.Ki & T.Ka & Jumlah \\
\hline Alphanokrim & 4934 & 4934 & 24670 & 4934 & 4934 & 44406 \\
Aphalanohoides & 14802 & 83879 & 113482 & 177624 & 49340 & 439126 \\
Chromodora & 4934 & 0 & 4934 & 0 & 9868 & 19736 \\
Pangnokrim & 59209 & 19736 & 19736 & 49340 & 49340 & 197360 \\
Paelionema & 19736 & 0 & 9868 & 0 & 4934 & 34538 \\
Daliohodors & 0 & 0 & 4934 & 4934 & 0 & 9868 \\
Grefiella & 0 & 0 & 4934 & 0 & 4934 & 9868 \\
Hais & 0 & 0 & 4934 & 4934 & 4934 & 14902 \\
Proseriata & 9968 & 4934 & 4934 & 44406 & 14802 & 78944 \\
Kalyptorhynohia & 0 & 0 & 0 & 4934 & 0 & 4934 \\
Chaetonatus & 4934 & 0 & 4934 & 9868 & 0 & 19736 \\
Dendrodanys & 0 & 0 & 0 & 4934 & 0 & 4934 \\
Platydasis & 0 & 0 & 0 & 9869 & 0 & 9869 \\
Jumlah & 119416 & 113492 & 197360 & 315776 & 143096 & 989120 \\
\hline
\end{tabular}

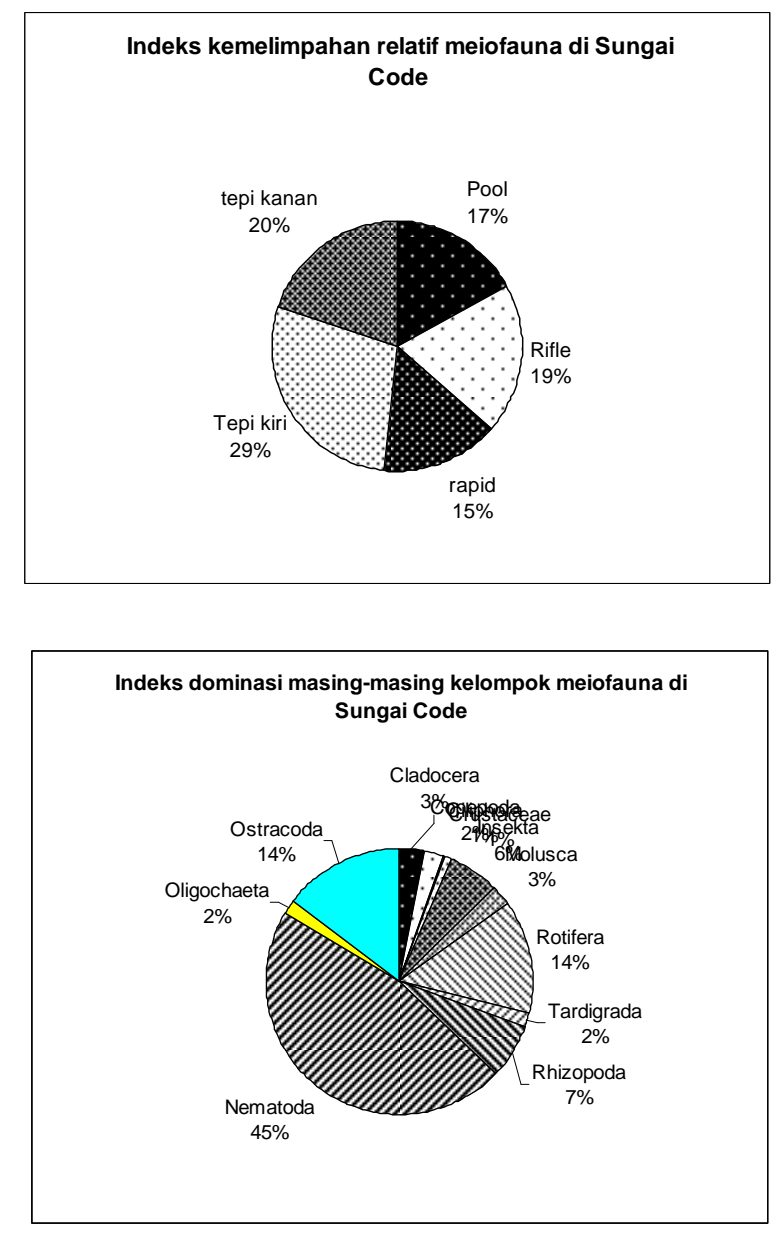

Faktor-faktor alamiah yang mempengaruhi komunitas meiofauna adalah garam-garam yang terlarut, arus, besarnya oksigen terlarut (DO), suhu, dan vegetasi di perairan tersebut. Hasil dari 
pengukuran kecepatan arus adalah $0,03 \mathrm{~m} /$ detik$0,49 \mathrm{~m} /$ detik. Kecepatan arus akan mempengaruhi komposisi hewan meiofauna di perairan dengan lambatnya arus ini maka hewan meiofauna yang ditemukan juga lebih banyak jika dibanding dengan perairan yang mempunyai arus yang kuat. Di sungai Code diketemukan 70 genera hewan meiofauna dan terbanyak di zona tepi kanan yaitu 40 genera

Oksigen terlarut digunakan oleh organisme untuk respirasi kelarutan oksigen dipengaruhi oleh suhu. Semakin tinggi suhu maka kelarutan oksigen semakin rendah. Oksigen terlarut pada Sungai Code sangat baik bagi kelangsunganhidup mikroorganisme

Dalam kasus ini DO bukan merupakan faktor pembatas karena kebanyakan meiobenthos dapat hidup dalam kondisi anaerob. Nilai alkalinitas Sungai Code berkisar antara 20 ppm sampai $25 \mathrm{ppm}$. Tingginya nilai alkalinitas berhubungan dengan tingginya $\mathrm{pH}$ perairan. Masih banyaknya masyarakat atau penduduk yang menggunakan air sungai untuk memenuhi kebutuhan sehari-hari seperti mandi, cuci sehingga banyak detergen yang terbuang ke dalam sungai dan akan menyebabkan nilai $\mathrm{pH}$ tinggi dan alkalinitas juga tinggi walau demikian perairan sungai code masih baik bagi kehidupan organisme meiofauna karena menurut Boyd (1982) dalam kristianto et al (1994) perairan dengan nilai alkalinitas $40 \mathrm{ppm}$ masih baik bagi proses-proses biologi organisme perairan

\section{KESIMPULAN}

1. Kemelimpahan meiofauna di sungai code di dominasi oleh kelompok Nematoda

2. Ditemukan 70 genera meiofauna dan jumlah spesies tertinggi terdapat pada zona tepi kanan daerah hulu sungai

3. Distribusi horizontal paling luas adalah dari kelompok Nematoda, Ostracoda, Rhizopoda dan Insekta

4. Kualitas fisik kimia perairan masih baik bagi kelangsungan hidup hewan meiofauna
DAFTAR PUSTAKA

Anonim 1985. Standard Methods for the Examination of Water and Wastewater 5 th ed. American Public Health Association, Washington

Goldman R, R and Horne A,J 1983. Limnology. Mc Graw Hill International Book Company, London

Haslam, SM 1990 River Pollution and Ecological Prespective. Belhaven Press London

Hawkes HA 1979 Invertebrates as Indicator of river water quality. John willey and Sons Ltd, London

Hellawel JM 1986 Biological Indicator of fresh water pollution and Environmental Management. Elsevier Applied science publishing London

Kovacs M 1992 Biological Indicator of Environmental Pollution Elles Honwood New York

Krisdianto, Tarmaji A dan Juhana S 1994. Pengaruh air Bangai terhadap beberapa aspek Fenomena Limnologi pada beberapa danau rawa di Kalimantan selatan. KPSL Unlam Banjarbaru

Robert P Higgins Hjalmar Thiel. 1988. Introduction to the Study of Meiofauna. Published by the Smathsonian Instituen Press. Washington DC 